\title{
REFERENCIAÇÃO, ARGUMENTAÇÃO E HUMOR EM ESQUETES ${ }^{1}$
}

\author{
REFERENCE, ARGUMENTATION AND HUMOR IN SKETCHES
}

\author{
Dean Lima ${ }^{2}$
}

\begin{abstract}
RESUMO: Neste trabalho, assumimos que os processos de apresentação e retomada recategorizadora "são indiciados por marcações contextuais várias, de diferentes aspectos semióticos, para atenderem a diferentes propósitos argumentativos" (cf. CAVALCANTE \& BRITO, 2016). Assim sendo, este trabalho se propõe a analisar o esquete "Reis magia", elaborado pelo coletivo humorístico "Porta dos Fundos" e publicado no youtube dias antes do Natal. No que concerne às hipóteses, temos o seguinte: a) os referentes são (re)construídos não só pelo material linguístico, mas também por outras semioses; b) as semioses que compõem os esquetes, ao participarem da (re)elaboração dos referentes, são fundamentais para a deflagração do humor $e$, por conseguinte, para a argumentação. A análise realizada mostra, sobretudo, que o discurso religioso moralista está sendo questionado e que as (re)categorizações propostas no esquete rompem com as expectativas e só podem provocar o humor quando confrontadas com esse discurso religioso moralista.
\end{abstract}

PALAVRAS-CHAVE: Argumentação; esquete; processos referenciais; humor.

ABSTRACT: In this work, we assume that the processes of presentation and recategorization "are indicted by various contextual markings of different semiotic aspects, to serve different argumentative purposes" (cf. CAVALCANTE \& BRITO, 2016). Therefore, this work intends to analyze the "Magic Kings" sketch, elaborated by the creative humorous collective "Door of Funds" and published on youtube days before Christmas. As regards the hypotheses, we have the following: a) the referents are (re) constructed not only by the linguistic material, but also by other semioses; $b$ ) the semioses that compose the sketches, when participating in the (re)elaboration of referents, are fundamental for the outbreak of humor and, therefore, for the argumentation. The above analysis shows, above all, that moralistic religious discourse is being put into check and that the (re)categorizations proposed in the sketch break with expectations and can only provoke humor when confronted with this moralistic religious discourse.

KEYWORDS: Argumentation; sketches; referential processes; humor.

\section{INTRODUÇÃO}

Neste trabalho, partimos de dois principais pressupostos: i) a construção dos referentes se dá num processo evolutivo, não linear e sob múltiplas âncoras e que, por isso, essa

\footnotetext{
${ }^{1}$ Este texto é fruto da pesquisa sobre o gênero esquete, feita na dissertação de mestrado deste pesquisador (LIMA, 2017), e uma versão mais detalhada da apresentação feita pelo pesquisador no $7^{\circ}$ Simpósio Internacional de Linguística, que aconteceu em São Paulo/SP, em setembro de 2017.

${ }^{2}$ Mestre em Estudos Linguísticos e Licenciado em Letras Português e Francês pela Universidade Federal do Espírito Santo.
} 
construção não pode ser pontuada em uma única expressão lexical ou semiose; e ii) os processos de apresentação e retomada recategorizadora "são indiciados por marcações contextuais várias, de diferentes aspectos semióticos, para atenderem a diferentes propósitos argumentativos" (cf. CAVALCANTE \& BRITO, 2016).

Assim sendo, neste trabalho, propusemo-nos a analisar o esquete "Reis magia", elaborado pelo coletivo criativo humorístico "Porta dos Fundos" e publicado no canal do youtube dias antes do Natal. No que concerne às hipóteses, temos o seguinte: a) os referentes são (re)construídos não só pelo material linguístico, mas também por outras semioses; b) há vários recursos que deflagram o humor nos esquetes, no entanto, alguns são mais recorrentes; e c) as semioses que compõem os esquetes, ao participarem da (re)elaboração dos referentes, são fundamentais para a deflagração do humor e, por conseguinte, para a argumentação.

A fim de cumprir tal propósito, o presente artigo encontra-se estruturado em três seções. Inicialmente, teceremos considerações sobre os aspectos multimodais e (re)construção de referentes. Em seguida, tratamos do humor e argumentação. Por fim, apresentamos uma proposta de análise do fenômeno referencial no esquete "Reis magia".

A análise realizada mostra, sobretudo, que o discurso religioso moralista está sendo questionado ao se fazer humor de questões relacionadas à religião. As (re)categorizações propostas no esquete rompem com as expectativas e só podem provocar o humor quando confrontadas com esse discurso religioso moralista.

\section{Aspectos multimodais e (re)construção de referentes ${ }^{3}$}

É recente, nos estudos em Linguística Textual, a incorporação dos elementos imagéticos, sonoros, plásticos, etc. na análise de fenômenos textuais. Com o avanço das pesquisas, o conceito de texto foi sendo alargado de modo a contemplar as produções multimodais (CAVALCANTE, 2012; RAMOS, 2011, 2012). Nesse sentido, passou-se a entender que a produção de sentidos se dá em/por usos efetivos da linguagem - aqui, incluemse os gêneros que circulam e se constituem em diferentes mídias (internet, teatro, rádio, cinema, televisão), e que, por isso, são necessariamente, multimodais - feitos por sujeitos ativos. Por isso a proposta dialógica da linguagem dá ênfase ao contexto sócio-histórico na produção de um gênero.

\footnotetext{
${ }^{3}$ Neste trabalho, utilizaremos o termo "multimodalidade", uma vez que o nosso corpus se constitui da imbricação de signos imagéticos, verbais e sonoros.
} 
Para abarcar as produções multimodais, Cavalcante \& Custódio Filho (2010) reajustam o conceito de texto postulado por Koch ([2004] 2009), eliminando o termo "linguístico", substituindo-o pelo termo "não-verbal" cujo resultado é o que segue:

A produção de linguagem verbal e não verbal constitui atividade interativa altamente complexa de produção de sentidos que se realiza, evidentemente, com base nos elementos presentes na superfície textual e na sua forma de organização, mas que requer não apenas a mobilização de um vasto conjunto de saberes (enciclopédia), mas a sua reconstrução e a dos próprios sujeitos - no momento da interação verbal (CAVALCANTE \& CUSTÓDIO FILHO, 2010, p. 9).

Nesse sentido, o que se postula é que a comunicação pode se estabelecer pela utilização das mais variadas semioses e não apenas pelo uso da linguagem verbal. A natureza do texto é multifacetada e sua materialidade se organiza sob diferentes combinações intersemióticas.

A todo o momento, criamos versões do mundo, resultantes de nossos conhecimentos, expectativas, crenças e experiências. Logo, os referentes construídos por nós "não preexistem 'naturalmente' à atividade cognitiva e interativa dos sujeitos falantes, mas devem ser concebidos como produtos - fundamentalmente culturais - dessa atividade" (APOTHÉLOZ E REICHER-BÉGUELIN, [1995] 2003, p. 228).

De igual modo, para a Gramática do Design Visual, as estruturas pictóricas "estão imbricadas com os interesses das instituições sociais dentro das quais as figuras são produzidas, circulam e são lidas" (KRESS \& VAN LEUWEEN, [1996] 2006, p. 45). As imagens e tudo aquilo de que se constitui um texto atendem a um propósito comunicativo.

De maneira semelhante a de textos predominantemente produzidos com a semiose verbal/escrita, nas produções multimodais, a construção/negociação do(s) sentido(s) se faz por meio do acionamento simultâneo e não linear de signos verbais, imagéticos, plásticos que se integram na materialidade textual e mobilizam conhecimentos prévios e desejavelmente partilhados.

É, pois, com a aproximação dessas teorias que podemos falar em introdução e reconstrução referencial imagéticas. Inicialmente (Figura 1) ${ }^{4}$, Maurício é introduzido, através de sua imagem estereotipada como travesti, distribuindo beijos para os carros que passam e buzinam; e com um semblante feliz. Porém, na sequência do esquete (Figura 2), quando sua verdadeira identidade é revelada, ele é imageticamente recategorizado como nervoso.

\footnotetext{
${ }^{4}$ Trata-se do esquete "Traveco da firma". É, pois, com base nele que tecemos nossos comentários.
} 


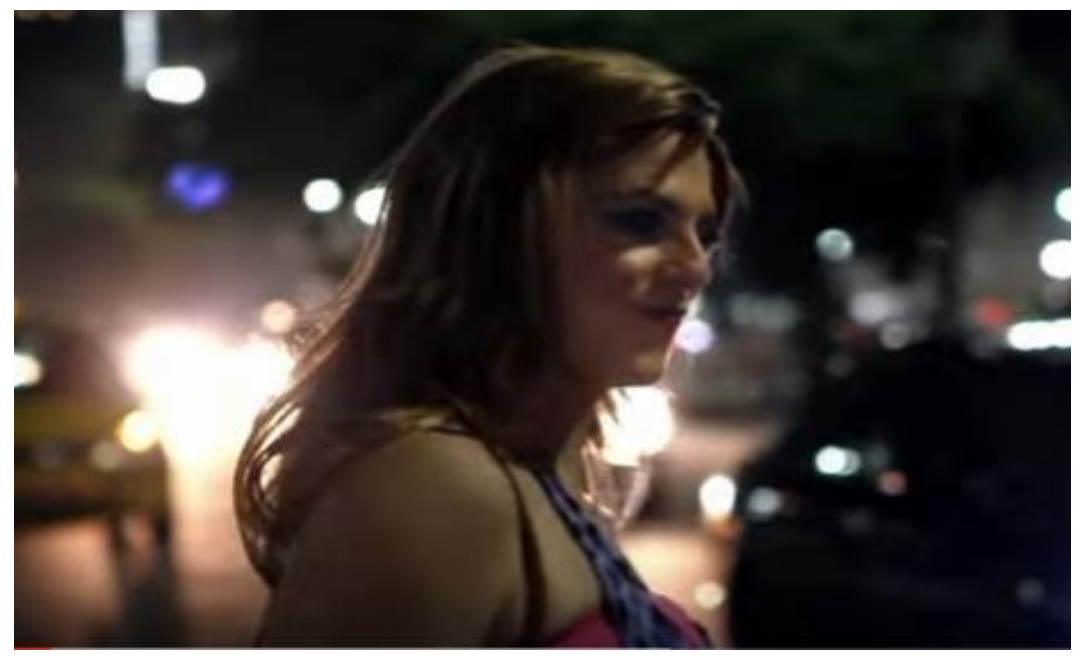

Figura 1 - Maurício aparece pela primeira vez (00:09 min)

Fonte: YOUTUBE. Porta dos fundos - TRAVECO DA FIRMA. Disponível em: 〈https://www.youtube.com/watch?v=Tv5b4JBGp-k>. Acesso em: 26 set. 2015.

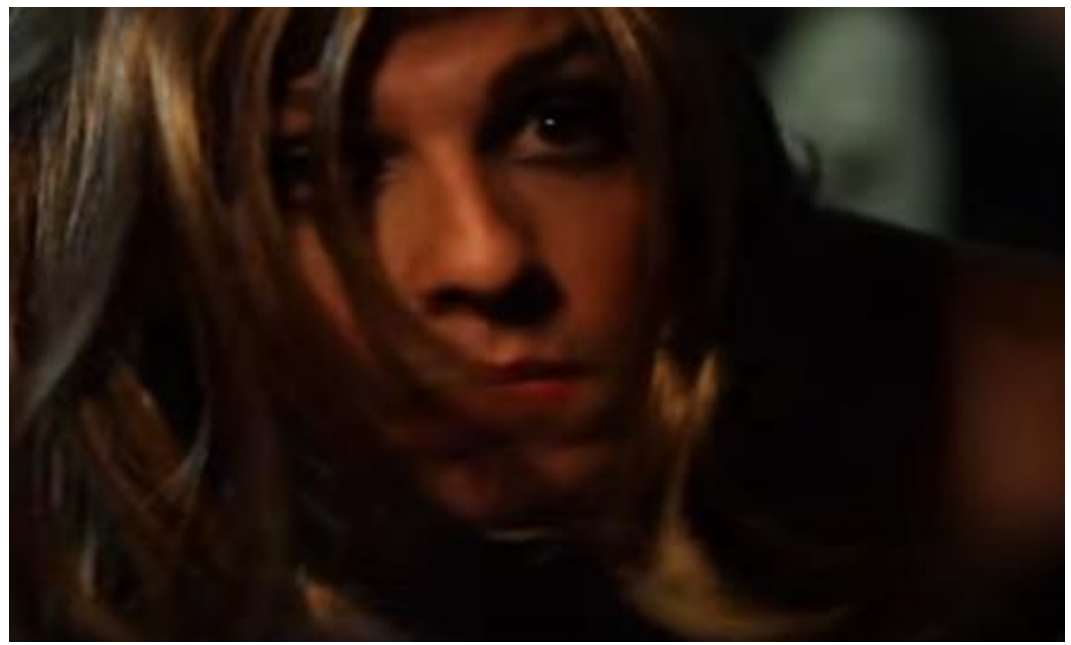

Figura 2 - Maurício nervoso com Jorge (00:45min)

Fonte: YOUTUBE. Porta dos fundos - TRAVECO DA FIRMA. Disponível em: <https://www.youtube.com/watch?v=Tv5b4JBGp-k>. Acesso em: 26 set. 2015.

Como é possível notar,

O olhar do participante (e o gesto, se presente) exige algo do espectador, exige que o espectador entre em algum tipo de relação imaginária com ele ou ela. Exatamente o tipo de relação que é então representado por outros meios, por exemplo, a expressão facial dos participantes representados. Eles podem sorrir, caso em que o espectador é convidado a entrar numa relação de afinidade social com eles; eles podem olhar para o espectador com desdém frio, caso em que o espectador é convidado a se relacionar com eles, talvez, como um inferior se relaciona a um superior; eles podem fazer beicinho sedutor para o espectador, caso em que este é convidado a desejá-los (KRESS \& VAN LEEUWEN, [1996] 2006, p. 118).

\section{Humor e argumentação}


Como temos defendido - neste e em outros trabalhos - o gênero esquete é necessariamente humorístico e os discursos nele encontrados desviam da dita seriedade/normalidade. No entanto, esse humor não é despretensioso, mas é através dele que se manifesta a orientação argumentativa dos esquetes. Aliás, nossas investigações apontam que o humor presente nos esquetes elaborados pelo "Porta dos fundos" assume sempre uma vertente argumentativa crítica.

Nesse sentido, importa destacar que a argumentação de que tratamos "envolve sujeitos, seus conhecimentos e formas de compreensão da realidade" (ELIAS, 2016, p. 192) e, por ser constituído de razão e vontade, "o homem constantemente avalia, julga, critica, isto é, forma juízos de valor" (p. 193), inclusive se valendo do humor para isso, como se objetiva mostrar neste artigo. Por essa razão, assim como postulam Koch (1987) e Koch e Elias (2016), assumimos que "o ato de argumentar, isto é, de orientar o que se diz para determinadas conclusões, constitui o ato linguístico fundamental” (p. 193).

E, se argumentar é uma atividade fundamentalmente linguística/discursiva

É, portanto, também por meio das palavras [...] que o orador deprecia, diminui, debocha, moteja, desdenha, desestima, humilha, desqualifica, desacredita, espezinha, escarnece, menospreza, avilta, ridiculariza... para provocar o riso. Nesse sentido, a depreciação (com todas as suas conotações negativas) consiste numa estratégia argumentativa para produzir humor e, consequentemente, atrair atenção (CARMELINO, 2014, p. 1430, grifos nossos).

Antes, porém, é importante salientar que muitas são as abordagens ${ }^{5}$ teóricometodológicas para os estudos de textos humorísticos. Ampliadas, aqui, para o estudo dos esquetes, um dado que tem chamado à atenção em nossas análises é a existência de situações inesperadas durante o desenrolar da história e que, por serem incongruentes, conduzem, inicialmente, o leitor para um caminho (muitas pessoas procuram travestis), mas o surpreende, logo em seguida, com o outro caminho tomado, não previsto (a descoberta de que o travesti era seu colega de trabalho, por exemplo).

Nesse sentido, do ponto de vista humorístico, o ridículo de uma pessoa, de um objeto ou de um comportamento é colocado em destaque de modo a provocar o riso, que só será alcançado se os conhecimentos de mundo forem ativados na mente dos interlocutores no momento da interação.

$\mathrm{Na}$ busca para compreendermos e explicarmos os mecanismos que propiciam a produção de humor nos esquetes, trazemos as contribuições de Raskin (1985) que, ao

\footnotetext{
${ }^{5}$ A esse respeito, indicamos dois trabalhos: o artigo de Travaglia (1990) e que mapeia algumas abordagens e o livro organizado por Carmelino (2015) que tem por objetivo expor algumas abordagens das pesquisas linguísticas sobre humor realizadas no Brasil.
} 
identificar que havia duas situações opostas em piadas, defendeu a tese de que todo falante dispõe de uma "competência humorística" e traçou a Semantic Script Theory of Humor, na qual definiu o humor como um ato de comunicação non-bona-fide, em oposição ao tipo de comunicação bona-fide.

Para Raskin (1985, p. 103-104), o humor, ao contrário do que se pensava, "parece ser a segunda forma de comunicação mais socialmente aceitável [...] após a comunicação bona fide", pois, ao ter contato com as piadas, o leitor já sabe que o que será dito tem por objetivo provocar o riso.

A base da teoria de Raskin é a noção de script, que é "uma porção organizada de informação sobre alguma coisa [...] uma estrutura cognitiva internalizada que proporciona ao falante informações sobre como as coisas são feitas, organizadas etc" (RASKIN, 1985, p. 198). A deflagração do humor se dará quando os dois scripts opostos forem substituídos, um pelo outro, a partir da descoberta, pelo leitor, de uma incongruência.

De acordo com essa teoria, para que um texto possa ser caracterizado como humorístico, ele precisa atender a dois princípios básicos: a) ser compatível com dois scripts diferentes; e b) esses dois scripts precisam ser opostos. No entanto, essa teoria, tal qual foi proposta por Raskin (1985), ficava restrita à análise de gêneros majoritariamente linguísticos.

Assim sendo, para analisar gêneros multissemióticos, Tafarello (2014) ampliou a noção de script, noção essa que adotaremos neste trabalho. Ao se propor a analisar o gênero tira cômica, Tafarello (2014) observou que a imagem também evoca scripts do senso comum, assim como os elementos verbais em gêneros puramente linguísticos. Desse modo, a autora assinala que o script "é uma ampla porção de informação semântica circundando a palavra e/ou a imagem ou evocada por elas" (TAFARELLO, 2014, p. 99, grifos nossos). Um dos exemplos analisados pela autora é a Figura 3:

MOTIUO DO BRASIL TER TOMADO 4 GOLS EM 6 MINUTOS
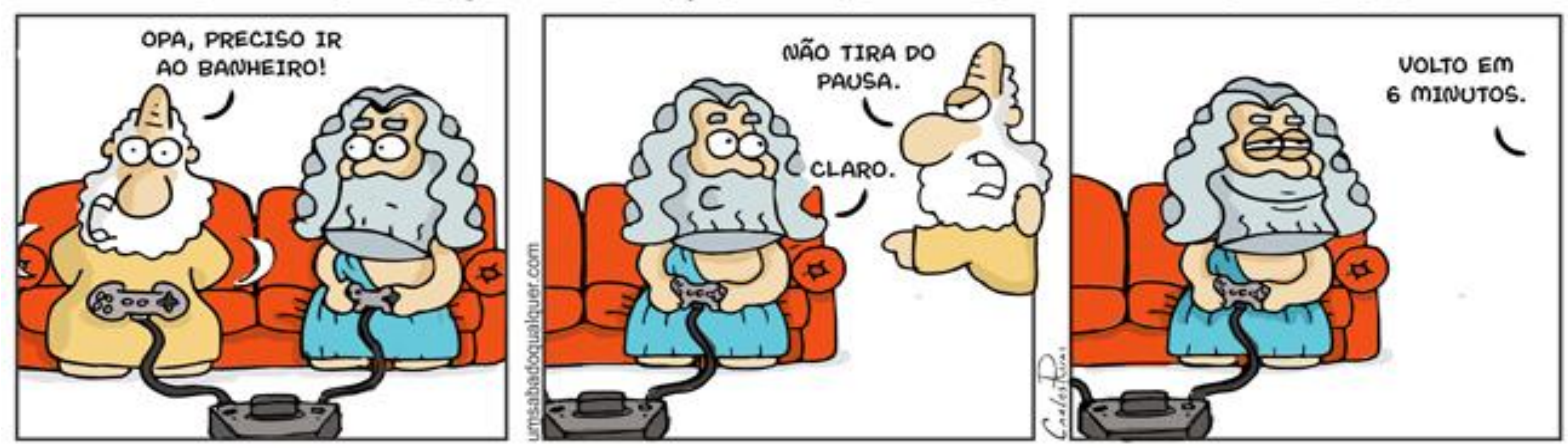

Figura 3 - tira cômica do blog Um sábado qualquer Fonte: RUAS, C. 1347 - Vacilão 3. Um sábado qualquer. 08 jul. 2014, 23h07min. 
O último quadro/cena exemplifica o que é defendido por Tafarello (2014) e que, a nosso ver, muito tem a contribuir para o nosso trabalho. $\mathrm{O}$ objeto de discurso Deus, que vinha sendo reconstruído imageticamente, some de cena, fato comprovado pela sua fala "volto em 6 minutos". Mas é "a imagem irônica de [Odin] que aciona o gatilho visual do humor, revelando os scripts de divindade vs imperfeição" (TAFARELLO, 2014, p. 101, grifos da autora). Em outras palavras, a tira brinca com o fato de Odin - deus mais importante da mitologia nórdica - roubar no jogo (fazer 4 gols) em apenas 6 minutos. Rimos, porque nos lembramos do fatídico jogo, na semifinal da Copa do Mundo, cujo placar foi Alemanha 7 x Brasil 1.

O que provocou a mudança de um script (divindade) para o outro (imperfeição), fazendo com que o leitor reinterpretasse a piada, chegando ao script oposto, foi a imagem. Isto é, em gêneros multissemióticos, além do linguístico, elementos como a imagem linguagem corporal, vestuário, cenário - e o som - voz, barulho - cooperam para a produção do humor, e, logo, conforme assinala Tafarello (2014), esses elementos também funcionam como gatilho visual/sonoro do humor.

Dessa forma, neste artigo, “o verbal é visto em paralelo com o visual e [...], juntos, os dois códigos nos permitem analisar não somente as falas, mas também movimentos dentro da encenação, posturas, sentimentos e estados de ânimos dos personagens" (LINS, 2015, p. 178) e mostrar que fazer humor é argumentar, é questionar um comportamento e/ou escancarar um mau costume.

\section{Uma proposta de análise}

Com o propósito de analisar que ao se fazer humor, argumenta-se, assim como mostramos na análise preliminar que fizemos de partes do esquete "Traveco da firma", selecionamos o esquete "Reis magia", que será analisado em sua integralidade, cujo enredo é o seguinte: em um ambiente que mais se parece com uma sala de estar, estão três reis magos mostrando, um ao outro, os presentes que irão dar ao menino Jesus que acabara de nascer em Belém. O primeiro a se manifestar é Melchior. Diz que vai dar ouro. Na sequência, Baltasar diz que vai dar incenso. Por último, fica Gaspar que rompe com o esperado e diz que vai dar um short com stretch e uma bata branca. Assustados, Melchior e Baltasar ainda tentam sugerir a Gaspar que ele dê outro presente, porém todas as alternativas dadas (uma echarpe, uma cinta, um berço e uma pintura de um cara nú) quebram as expectativas e acabam por serem reprovadas. Até que, por último, Gaspar sugere dar mirra e a história parece que terá outro 
desfecho. No entanto, novamente, somos surpreendidos com a justificativa que Gaspar apresenta pra ter mirra em casa: é bom pra fazer a chuca. Assim, o esquete termina com Jesus, já adulto, vestindo os mesmos trajes que iria receber de Gaspar: bata branca e short e recusando o jumento, sugerido por Maria - já que não encontra a bicicleta para sair -, em nome da proteção aos animais.

Diferentemente de alguns esquetes, este, logo de início, já nos fornece ricas informações. O título é um trocadilho da expressão "boy magia" e isso já é o suficiente para provocar humor no leitor e vontade de assistir ao esquete por completo. Observa-se que o trocadilho é com a palavra "reis", no plural, e que, para alguns leitores, a inferência será com os três reis magos da Bíblia. Além disso, este esquete parece já começar com o modo de comunicação non-bona-fide e com a introdução do referente reis. A primeira cena é a que segue:

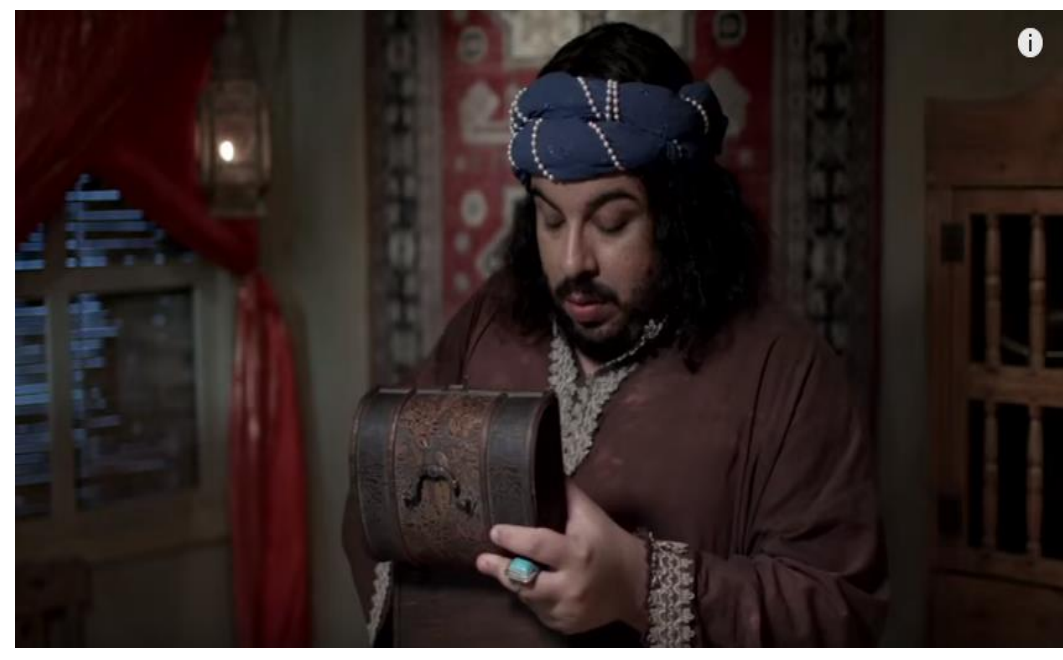

Figura 4 - cena inicial (00:00 min)

Fonte: YOUTUBE. Porta dos fundos - REIS MAGIA. Disponível em: 〈https://www.youtube.com/watch?v=_7iZF0wwA5c>. Acesso em: 19 dez. 2016.

Conforme Figura 4, vê-se um homem mexendo em uma caixa e, nos minutos subsequentes, entra em cena, correndo, outro homem. Inferimos, mais uma vez, que sejam dois reis magos, pois as imagens - barba e cabelos longos, roupa, turbante, cenário, entre outras - assim sugerem e, de modo mais saliente, introduzem o referente imagético. Nossa hipótese se confirma já no primeiro diálogo que eles travam. Ei-lo:

GASPAR - (entra saltitante) Gente ... banho quente ...

MELCHIOR - Vamos lá ... Oh, tamo atrasado ...

GASPAR - Claro que tamo atrasado ... botei a primeira roupa que vi, não deu tempo nem de maquiar (cheio de trejeitos, faz um movimento de pincel no rosto).

\footnotetext{
${ }^{6}$ Expressão muito utilizada entre os jovens. Refere-se a homens bonitos, charmosos, gostosos e cobiçado por todos.
} 
MELCHIOR - Tá, comprou os presentes?

GASPAR - (coloca as duas mãos na cintura como se estivesse debochando) Não?!

Não, Melchior! Não comprei. ( grita) Ah! Os pre ... claro que eu comprei ... não

comprei em agosto?! Fui o primeiro ... comprei. Vai dar o quê? (transcrição nossa)

Nesse diálogo primeiro, conseguimos, pela mudança no enquadre da câmera, ver melhor as roupas que os personagens estão vestindo. Além disso, aquele personagem, que apareceu primeiro, pergunta ao que chegou correndo se ele comprou o presente e, na resposta, ouvimos o nome Melchior. Todas essas informações confirmam as nossas inferências iniciais de que aqueles personagens se tratam dos Reis magos, e de que o título já é uma brincadeira. A articulação entre as diferentes semioses, sem que uma se sobreponha à outra, é que nos auxilia na produção dos sentidos desse esquete.

Assim, chamamos atenção para três pontos importantes. Primeiro: para a leitura desse esquete, inferimos e acionamos conhecimentos de mundo cristão ocidental, pois identificar que se trata de Reis magos não é o suficiente para compreender o gênero como um todo.

$\mathrm{O}$ que vem na sequência continua por elaborar os referentes e provocar o humor. Em resposta a Gaspar, Melchior mostra o presente que vai dar. É ouro. Nesse momento, entra em cena mais um homem, anáfora indireta, com trajes semelhantes ao dos outros dois personagens. Ele, de pronto, já exibe o que vai dar como presente. É incenso. Assim são o diálogo e os prints desses dois momentos:

MELCHIOR - (abre a caixa que está em sua mão) Ouro.

GASPAR - (faz cara de surpresa) Ah ... mentira, arrazô! Ouro voltou com tudo, neh?!

MELCHIOR - É ...

GASPAR - O dourado é a nova safira ... nova esmeralda. Ah, vou até levar um pra mim.

BALTASAR - (chega em cena) É ... muito bonito. (enquanto fala, levanta o que tem em mãos) Eu vou dar incenso ...

GASPAR - (bate a palma das mãos) Ah, eu amo ... cheirinho gostoso, deixa eu sentir, deixa eu sentir (se aproxima do presente para sentir o cheiro).

BALTASAR - Aqui (chega com o presente perto de Gaspar).

GASPAR - Isso é o que? Alfazema? É lavanda! ...

BALTASAR - Lavanda

GASPAR - É lavanda ... eu adoro! (transcrição nossa) 


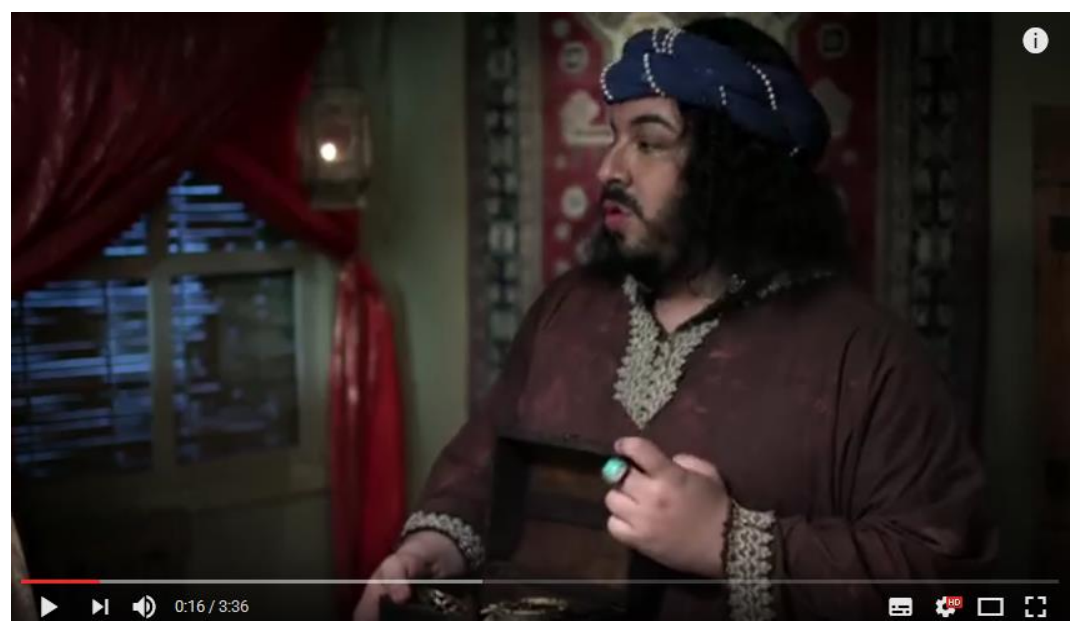

Figura 5 - Melchior mostra seu presente (00:16 min)

Fonte: YOUTUBE. Porta dos fundos - REIS MAGIA. Disponível em: <https://www.youtube.com/watch?v=_7iZF0wwA5c>. Acesso em: 19 dez. 2016.

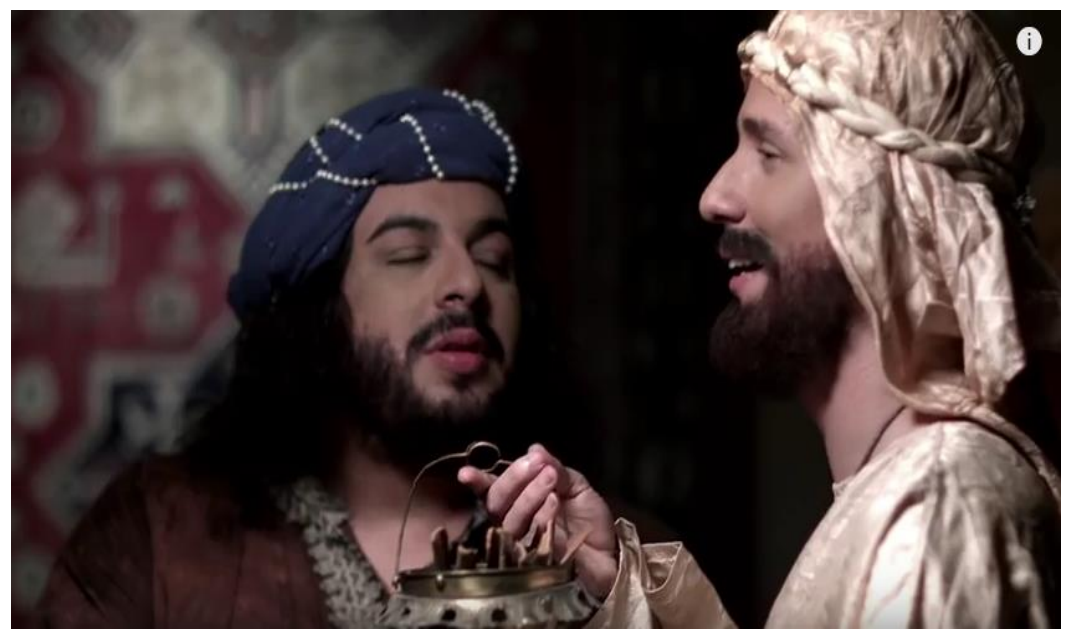

Figura 6 - Baltasar mostra seu presente (00:33 min)

Fonte: YOUTUBE. Porta dos fundos - REIS MAGIA. Disponível em: <https://www.youtube.com/watch?v=_7iZF0wwA5c>. Acesso em: $19 \mathrm{dez} .2016$.

Diante das muitas informações em poucos minutos de vídeo, se faz necessário fazer uma pausa para tecermos alguns comentários. Até esse momento do esquete, o leitor teve de fazer algumas inferências e se valer de seus conhecimentos prévios e de mundo. Não apenas conhecimentos de que as vestimentas são características de reis magos, mas que se trata dos três reis magos descritos na Bíblia. Segundo, todos os referentes foram introduzidos pela semiose imagética. Posteriormente, através do diálogo, um deles é chamado de Melchior e tomamos conhecimentos dos presentes que dois deles irão dar: ouro e incenso. Essas pistas confirmam que o esquete conta a história dos três reis magos que, segundo a Bíblia, dão presentes a Jesus no dia de seu nascimento.

$\mathrm{O}$ esquete continua: 


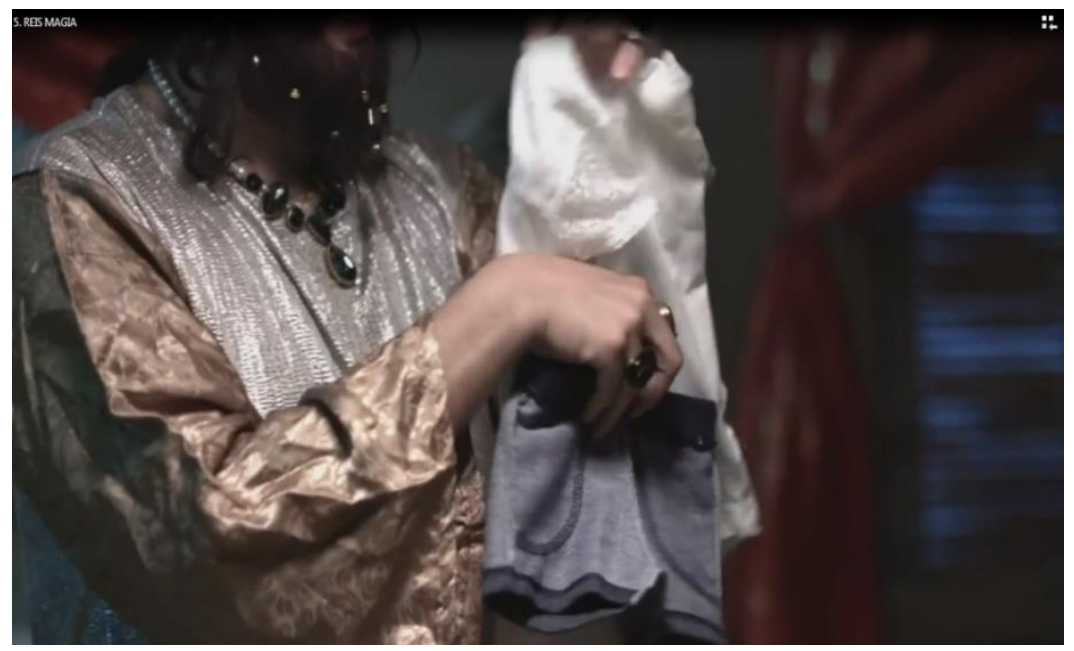

Figura 7 - Gaspar mostra seu presente (00:59 min)

Fonte: YOUTUBE. Porta dos fundos - REIS MAGIA. Disponível em: <https://www.youtube.com/watch?v=_7iZF0wwA5c>. Acesso em: 19 dez. 2016.

Eis o diálogo:

GASPAR - (vira para o lado e pega seu presente) Eu vou dar simplesmente esse shortinho jeans (gesticula para mostrar as qualidades do presente) stretch ... double face. MELQUIOR - Gaspar ...

GASPAR - Calma, não é só isso. Ih, ta achando que eu vou aparecer com o filho de Deus com shortinho?! E trouxe essa batinha branca (mostra para eles) toda grapeadinha que eu mesmo cozi. Hein, agora ... me conta se não vira uma coisa maravilhosa ele andandinho assim?! Ele correndinho?! (transcrição nossa)

O esquete continuou e temos informações novas e velhas: os referentes permanecem em saliência, enquanto Gaspar apresenta o presente que vai dar, anáfora indireta que está ancorada em "presentes". Algumas acrescentam informações à leitura do esquete. Vemos, pelos signos imagéticos, que os personagens continuam em cena, conversando sobre os presentes que irão dar. Ficamos sabendo que um deles se chama Gaspar e o diálogo entre eles vai evidenciando as nossas inferências: aqueles três homens são os três reis magos (Gaspar, Melchior e Baltasar) que dão presentes (incenso, mirra e ouro) ao menino Jesus, no dia de seu nascimento.

O humor advém do caminho diferente da história oficial que o esquete toma: ao invés de dar mirra, único presente que faltava ser mencionado, Gaspar diz que vai dar um shortinho jeans double face, com stretch, e uma bata branca. Ou seja, de comunicação bona-fide, a narrativa passa para a non-bona-fide. Quebra-se a expectativa do leitor e deflagra-se o humor quando tomamos conhecimento de que o terceiro rei mago irá dar uma bermuda e uma bata (ambos anáforas indiretas, ancoradas em presentes) para Jesus. Isso pode ser comprovado pelas expressões faciais de reprovação que recatecorizam os outros dois reis magos, no 
momento em que ouvem qual o presente que Gaspar pretender dar a Jesus. Gaspar ainda tenta justificar sua escolha:

GASPAR - tá nada esquisito. É que vocês não tem noção de moda. Só se usa isso em Nova Galileia. É que vocês vão dormir cedo. Quando dá 4 da manhã, o que aparece de homem usando essas batinha, tudo suado dançando ... Pelo amor de Deus! Jesus vai arrazar. Eu quero um Jesus boy magia ... um Jesus boy xxxxx, imagina ele na crechezinha dele (fala olhando para as roupinhas), andandinho assim sob as águas (mostra as roupas, simula andar)

BALTASAR - Gaspar, olha só, o que a gente tá pedindo pra você é o seguinte: levar uma coisinha um pouco menos cheguei ... (transcrição nossa).

Com a justificativa de Gaspar para dar aquele presente, finalmente, aparece o nome “Jesus", porém, esse referente que já estava inferível pelos nossos conhecimentos aparece com a predicação "boy magia", a mesma do título, e essa recategorização também provoca o humor. Porém, Gaspar não consegue convencê-los e seus amigos sugerem que ele leve "uma coisinha um pouco menos cheguei”, anáfora direta de presente, e também contribui para o humor, uma vez que o adjetivo "cheguei" na fala de Baltasar refere uma preferência por figurinos ligados à cultura gay, o que torna o termo um trocadilho: che-gay (preconceituosamente: chegar como chegaria um gay). Contrariado, ele sugere algumas coisas (echarpe, cinta, sandalinha de salto), mas seus amigos não concordam muito. Por fim, ele sugere dar uma obra de arte:

GASPAR - obra de arte dá uma levantada naquela manjedoura ...

BALTASAR - isso aí ...

GASPAR - (abaixa e pega um objeto) eu mesmo pintei aqui um quadro que eu acho que vale a pena ... (descobre a pintura) ... acho que eles vão amar.

BALTASAR - oh, oh, Meu Deus! (Melchior vira o rosto)

GASPAR - eu achei que pode tá um pouco exagerado no azul, mas eu achei lindo ... uma coisa impressionista ... esse aqui é "NUNO" (fala apontando pra pintura)

BALTASAR - é quem, Gaspar?

GASPAR - Nuno é um rapaz que vem aqui quarta-feira. Ele que dá a geral aqui na casa ... vocês não estão aqui geralmente. Tô até pedindo pra ele vir di sábado agora também ... ele é excelente. (aponta para o quadro) Eu pensei que, de repente aqui, podia dar uma coisinha no vermelho. (transcrição nossa).

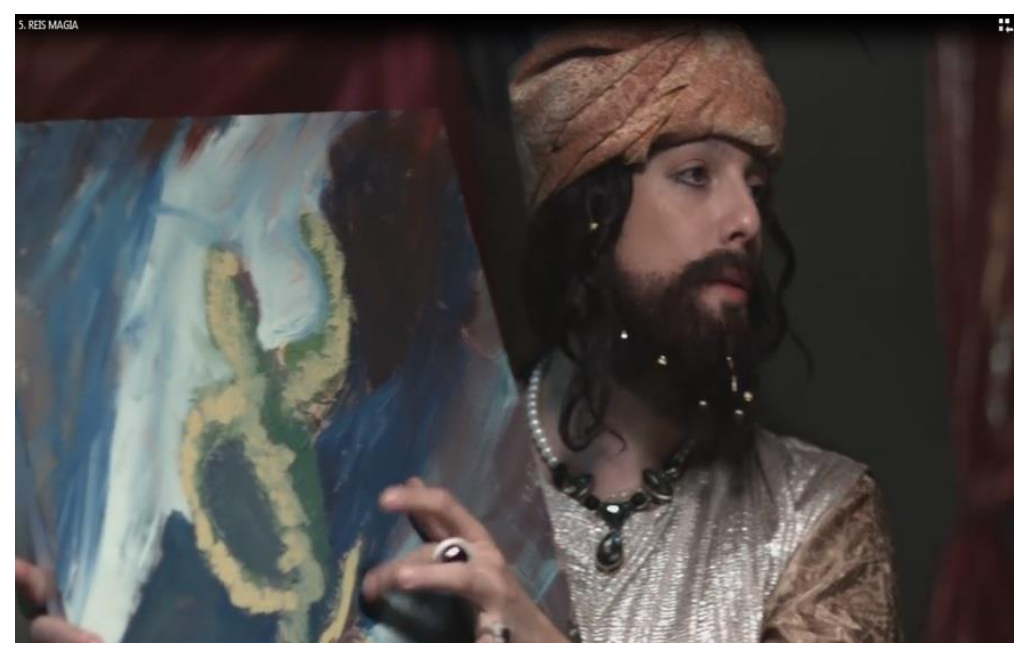


Figura 8 - Gaspar mostra a pintura (02:21 min)

Fonte: YOUTUBE. Porta dos fundos - REIS MAGIA. Disponível em: <https://www.youtube.com/watch?v=_7iZF0wwA5c >. Acesso em: $19 \mathrm{dez} .2016$.

Gaspar então mostra a pintura que ele mesmo fez e Belchior e Baltasar, ao olharem o que está pintado, desviam o olhar imediatamente. O leitor então se dá conta de que o quadro é a pintura de um homem com o órgão sexual ereto. Mais uma vez a expectativa é quebrada e o humor é deflagrado quando Gaspar ainda explica que gostaria de pintar de vermelho "aqui", e aponta, conforme Figura 8, para o pênis no quadro. Dêitico recuperável apenas quando se tem contato com a imagem do esquete.

Melchior se estressa com essa atitude de Gaspar, e essa recategorização encontra reforço, além do tom de voz firme, no olhar, olhos abertos, e no gestual: imediatamente tentar tomar o quadro da mão de Gaspar. Destacamos que em textos multimodais, diferentemente dos textos prototípicos, as retomadas se dão pelo signo icônico.

Muitas são as tentativas de se achar um presente adequado ao momento. Por fim, Gaspar decide dar mirra e, imediatamente, nossas inferências recuperam esse referente em nossos conhecimentos de mundo e percebemos que, finalmente, Gaspar irá levar o presente descrito na Bíblia e que faltava até o momento (Baltasar iria dar incenso e Melchior, ouro). O esquete continua:

GASPAR - ah, então eu vou dar mirra.

BALTASAR - então vamos que a gente está atrasado ...

GASPAR - (fala olhando para o objeto) mirra ...

BALTASAR - vamos ...

MELCHIOR - (interrompe Baltasar) então, só pra saber, por que você tem mirra?

GASPAR - é bom pra fazer a chuca. Mas esse aqui já tá lavado. Vamos que a estrela vai passar a qualquer momento (olha pro lado e diz sorrindo) olha ela lá ... loca ... (sai de cena gritando) vem aqui ... (ouve-se risos. Belchior e Baltasar demonstram não estar satisfeitos) (transcrição nossa).

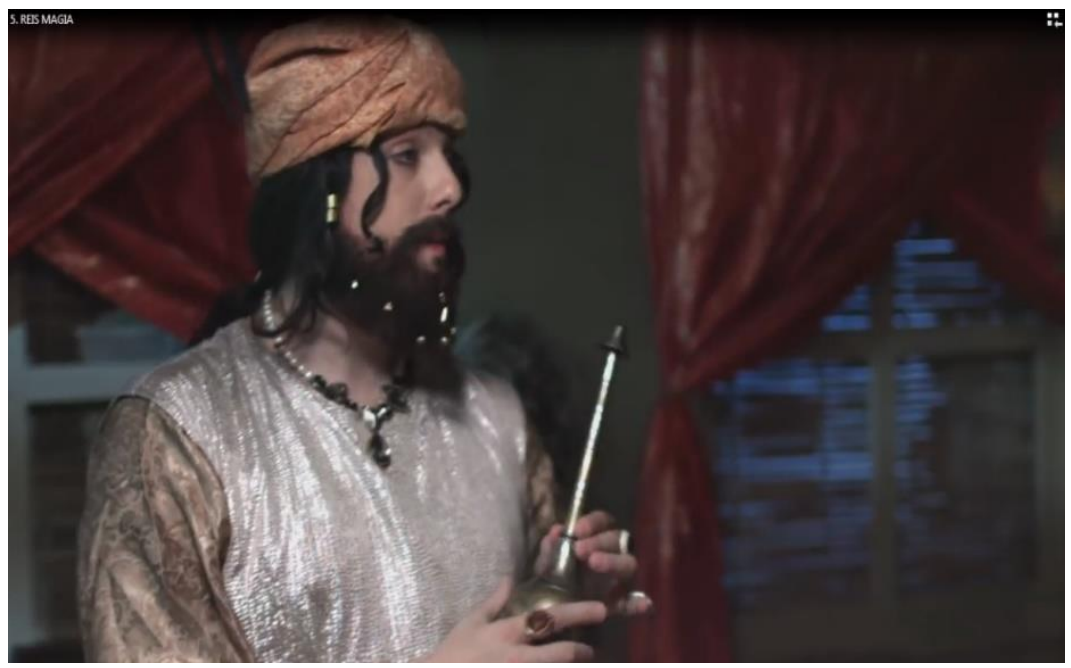


Figura 9 - Gaspar mostra a mirra (02:15 min)

Fonte: YOUTUBE. Porta dos fundos - REIS MAGIA. Disponível em: <https://www.youtube.com/watch?v=_7iZF0wwA5c>. Acesso em: 19 dez. 2016.

Escolhido o presente, todos comemoram, porém, antes de írem ao encontro de Maria, José e do menino Jesus, Melchior pergunta o porquê de Gaspar ter mirra e a resposta de Gaspar, mais uma vez, rompe com o esperado: “é bom pra fazer a chuca. Mas esse aqui já tá lavado". O leitor então aciona o conhecimento prévio de que o referente chuca ${ }^{7}$ é um procedimento adotado, quando se quer ter relação sexual anal, que tem por objetivo lavar o ânus e o reto. Deflagra-se, portanto, o humor disso. A predicação da retomada anáfora, "esse aqui já tá lavado", também colabora para a deflagração do humor. Ou seja, o presente que será dado a Jesus é um material que já foi introduzido no ânus de um dos reis magos, mas foi limpo.

O esquete é interrompido e, na sequência, retorna com a imagem e diálogo a seguir:

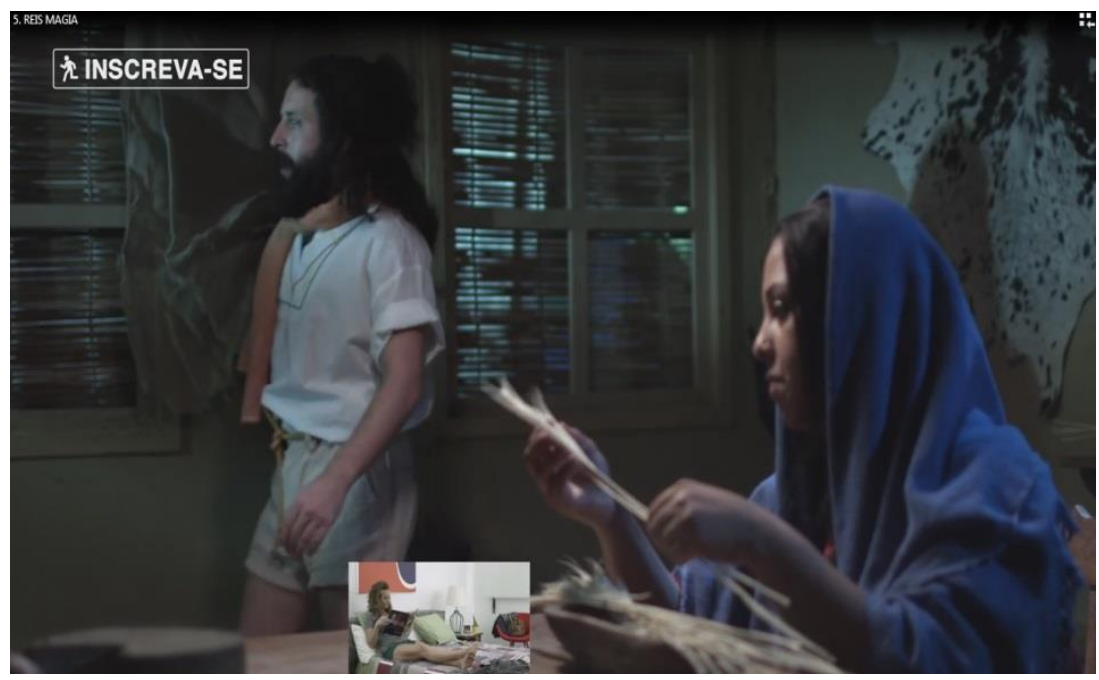

Figura 10 - Jesus e Maria (03:17 min)

Fonte: YOUTUBE. Porta dos fundos - REIS MAGIA. Disponível em: <https://www.youtube.com/watch?v=_7iZF0wwA5c>. Acesso em: 19 dez. 2016.

A cena muda. Há novas informações visuais. Esse momento cria a expectativa no leitor de que o desfecho do esquete será inesperado e levará ao humor. Para compreendermos a retomada anafórica do referente, precisamos fazer algumas inferências. Um referente é introduzido imageticamente, porém parece já ser conhecido pelo leitor. A semelhança se dá pela vestimenta do personagem: short, bata branca, uma echarpe laranja e cinto. O outro

\footnotetext{
${ }^{7}$ Esse termo, devido a sua popularidade, já se encontra dicionarizado. No Dicionário inFormal, registra-se da seguinte maneira: "Enema ou chuca. Prática da medicina também chamada de hidrocolonterapia que consistem em introduzir uma mangueira no anus da pessoa, injetar água e depois retirar" (DICIONÁRIO INFORMAL)
} 
referente, também introduzido imageticamente, é uma mulher, com um manto azul sobre a cabeça que está sentada colhendo trigo. Além disso, o espaço é outro: parece um casebre, há algumas janelas de madeira, uma mesa e pouca luz.

De posse dessas informações novas, os leitores compreendem que aquele homem é Jesus, mais velho (informação recuperada no processamento textual), e aquela mulher, sua mãe, Maria. Porém o desfecho é inesperado, ou seja, o que leva ao humor é a recategorização imagética do referente Jesus: ele está com roupas semelhantes as que o rei mago Gaspar queria presenteá-lo quando nasceu. E, rimos, pois, como é próprio da comunicação non-bonafide, não é de se esperar que o salvador use esses trajes modernos. A imagem que construímos através de nossos conhecimentos de mundo nos faz inferir outra vestimenta para Jesus.

\section{Considerações finais}

Neste trabalho, procuramos evidenciar o papel de elementos linguísticos e imagéticos no processo de referenciação e como, nessa imbricação, eles atuam de modo a deflagrar o humor que, por sua vez, é um recurso utilizado para atender "a diferentes propósitos argumentativos", como por exemplo, tencionar os campos da religião e gênero (homossexualidade) dentro da mídia. Com humor, questiona-se o discurso "religioso refratário a manifestações da sexualidade que escapam à norma heterossexual" (NATIVIDADE, 2009, p. 124).

Assim sendo, com nossa análise, foi possível demonstrar que o contexto e a (re)construção dos referentes orientam o leitor de modo que se estabilize uma imagem estereotípica de homens gays. Colaboram para as quebras de expectativa, características dos gêneros humorísticos, tanto expressões referenciais como imagens. Assim, a chave para compreender o final imprevisto, fonte da comicidade, não se ancora apenas em um código semiótico.

\section{REFERÊNCIAS}

APOTHÉLOZ, D. e REICHLER-BÉGUELIN, M. J. Construction de la référence et stratégies de désignation. In: BERRENDONNER, A. e REICHLER-BÉGUELIN, M. J. (eds.) Du syntagme nominal aux objets de discours. SN complexes, nominalizations, anaphores. Neuchâtel: Institute de Linguistique de Neuchâtel, p. 227-271, [1995] 2003.

CARMELINO, A. C. Humor: eis a questão. São Paulo: Cortez, 2015. Motivos para (não) ler a MAD: estratégias argumentativas no texto de humor. Estudos Linguísticos (São Paulo. 1978), v. 43, p. 1426-1438, 2014. 
CAVALCANTE, M. M. Os sentidos do texto. São Paulo: Editora Contexto, 2012.

\& BRITO, M. A. P. O caráter naturalmente recategorizador das anáforas. In: AQUINO, Z. G. O.; GONÇALVES-SEGUNDO, P. R. (Orgs.). Estudos do discurso: caminhos e tendências. São Paulo: Paulistana, 2016. Disponível em: http://cied.fflch.usp.br/sites/cied.fflch.usp.br/files/u31/Livro-CIED-2016-final.pdf. Acesso em: 25 nov. 2016.

\& CUSTÓDIO FILHO, V. Revisitando o estatuto do texto. Revista do GELNE, v. 12, p. 56-71, 2010.

ELIAS, V. M. Estudos do texto, multimodalidade e argumentação: perspectivas. ReVEL, edição especial, vol. 14, n. 12, 2016). Disponível em: http://www.revel.inf.br/files/5468c9d9679da7cfe81f9c8725fecc11.pdf. Acesso em: 25 nov. 2016.

KOCH, I. G. V. Introdução à linguística textual: trajetória e grandes temas. São Paulo: Martins Fontes, [2004] 2009. . Argumentação e linguagem. São Paulo: Cortez, 1987. . ELIAS, V. M. Escrever e argumentar. São Paulo: Contexto, 2016.

$\overline{\text { KRESS }}$, G. \& VAN LEEUWEN, T. Reading images: the grammar of visual design. London: Routledge, [1996] 2006.

LIMA, D. G. G. O processo de (re)construção de objetos de discurso e a produção do humor em esquetes do coletivo criativo 'Porta dos fundos'. $125 \mathrm{f}$. Dissertação (Mestrado em Linguística) - Universidade Federal do Espírito Santo, Centro de Ciências Humanas e Naturais, 2017.

LINS, M. da P. P. Os contos de fada na visão de Mafalda: ou até quando vamos ser os frangos da literatura?. In: CARMELINO, A. C. (org.). Humor: eis a questão. São Paulo: Cortez, p. 112-127, 2015.

NATIVIDADE, M. T.; OLIVEIRA, L. de. Sexualidades ameaçadoras: religião e homofobia (s) em discursos evangélicos conservadores. Sexualidad, Salud y Sociedad: Revista Latinoamericana, vol. II, p. 121-161, 2009. Disponível em: http://www.epublicacoes.uerj.br/ojs/index.php/SexualidadSaludySociedad/article/view/32/154. Acesso em: 25 nov. 2016.

PORTA DOS FUNDOS. Porta dos fundos. Rio de Janeiro: Sextante, 2013.

RAMOS, P. E. Estratégias de referenciação em textos multimodais: uma aplicação em tiras cômicas. Ling. (dis)curso [online]. 2012.

Faces do humor: uma aproximação entre piadas e tiras. Campinas, SP: Zarabatana Books, 2011.

RASKIN, V. Semantic mechanisms of humor. Holland: D. Reidel Publishing Company, 1985.

TAFARELLO, M. C. M. de. Quadrinhos e scripts. In: LINS, M. da P. P.; SOUZA JUNIOR, R. C. (orgs.). Quadrinhos sob diferentes olhares teóricos. Vitória: Ufes, Programa de PósGraduação em Estudos Linguísticos, p. 87-105, 2014.

TRAVAGLIA, L. C. Uma introdução ao estudo do humor pela linguística. DELTA - Revista de Documentação de Estudos em Linguística Teórica e Aplicada, São Paulo, v. 6, n. 1, p. 55$82,1990$.

Recebido em 31/03/2018. Aceito em 06/06/2018. 